\title{
Uma trama tecida com muitos fios: o pesquisar como processo artesanal na Teoria Ator-Rede
}

\section{A plot woven with many threads: the handcraft process of researching in the Actor-Network Theory}

\section{Una trama tejida con muchos hilos: la investigación como proceso artesanal en la Teoría del Actor-Red}

\section{Laura Cristina de Toledo Quadros*}

Universidade do Estado do Rio de Janeiro - UERJ, Rio de Janeiro, Rio de Janeiro, Brasil

\begin{abstract}
RESUMO
O presente artigo pretende discutir a experiência de pesquisar como uma prática artesanal, tendo como referência metodológica a Teoria ator-rede que, através de sua proposta, nos permite compreender que a pesquisa está sujeita a desvios e recalcitrâncias. Considerando o pesquisar como um processo único, onde cada campo convoca peculiaridades e ações diferenciadas, aproximamos essa prática à construção artesanal em que o fazer também se constitui de modo não linear. A inspiração artesanal eleita como base foi a arte de tecer com fios, em especial a arte de "crochetar", emergindo aqui uma herança feminina que nos atravessa. Compreendemos que os modos de fazer só podem ser acompanhados na prática, e nos interessa discutir como se processa o pesquisar articulado à vida como uma política ontológica.
\end{abstract}

Palavras chave: pesquisa, teoria ator-rede, política ontológica, prática de pesquisa.

\begin{abstract}
In this paper we intend to discuss the experience of researching as a handcraft practice referenced in the Actor-Network Theory (ANT), which gives us the understanding that a research may have deviations and recalcitrancy. Researching is an unique process, in which each field implies peculiarities and differentiated actions. We linked this practice to a handcraft doing in which procedure we don't have a linear path. We chose the 'crochet' - art of weaving with threads - as a feminine heritage that involves ourselves. As we understand that the modes of doing can only be followed in their own practice, we intend to discuss the process of researching in articulation with life, as an ontological politics.
\end{abstract}

Keywords: research, actor-network theory, ontological politics, practices in research.

\section{RESUMEN}

El presente artículo pretende discutir la experiencia de investigar como una práctica artesanal, teniendo como referencia metodológica la Teoría del Actor-Red (TAR), la cual, a través de su propuesta, nos permite comprender que la investigación está sujeta a desvíos y recalcitrancias. Considerando la investigación como un proceso 
único, donde cada campo trae consigo peculiaridades y acciones diferentes, aproximamos esta práctica a la construcción artesanal, en que el "hacer" también se constituye de modo no-linear. La inspiración artesanal escogida como base fue el arte de tejer a crochet, que emerge en esta discusión como una herencia femenina que nos atraviesa. Comprendemos que los modos de hacer solamente pueden ser acompañados en la práctica, y nos interesa discutir el proceso de investigación articulado a la vida como una política ontológica.

Palabras claves: investigación, teoría del actor-red, política ontológica, prácticas de investigación.

\section{I ntrodução}

O presente artigo pretende discutir a experiência de pesquisar como uma prática artesanal, tendo como referência metodológica a Teoria ator-rede (TAR) que, através de sua proposta, nos permite compreender que a pesquisa está sujeita a desvios e recalcitrâncias. Inicio situando o leitor no ponto de partida dessa reflexão que foi investigar a prática clínica em psicologia compreendida aqui como uma construção artesanal. Nosso interesse foi acompanhar como se processa tal construção através de seus fazedores. Ressalto, no entanto, que a intenção deste artigo não é apresentar os procedimentos ou discutir os resultados da pesquisa. O que nos move nessa escrita são as descobertas dos acontecimentos, as afetações que foram construindo esta pesquisadora. Trata-se, portanto, de descrever o percurso com suas tensões e arranjos, o labirinto e as saídas possíveis nesse encontro entre o pesquisador e seu campo. Consideramos, então, que nossa discussão atém-se ao pesquisar como verbo e substantivo tal como proposto por Moraes (2011) quando ela nos aponta que, embora seu modo de atuar a incline a afirmar o pesquisar como verbo "... os substantivos me tomam de assalto: hesitação, solavanco, angústias, as paradas, os impasses, os mal entendidos." (p.175). Assim, no rastro da autora citada interessa-me aqui dialogar a partir dos impasses que forjam 0 pesquisador e do movimento que vai sendo desenhado nas redes que ele tece enquanto atua. .Porém, a guisa de incluir o leitor e permitir que ele nos siga mais de perto, apresentarei sucintamente o cenário no qual se desenrolam nossos embates e deleites.

A prática clínica atravessa meu percurso de diversas formas. Vejome na multiplicidade de ser psicóloga clínica atuando em diversos segmentos, docente e supervisora de estágio na área, cliente, formadora de novos terapeutas, enfim implicada, intrigada, bem como questionadora dessa prática. Por ser este um campo dinamizado por muitas forças, a prática clínica, mesmo em abordagens mais diretivas e/ou pré formatadas, não pode garantir uma "produção industrial de efeitos terapêuticos" porque depende também do que é produzido pelo outro - o cliente/ paciente. O efeito e 
os recursos de um processo terapêutico não é algo possível de prever. Envolvida nessa trama, adentrei este território entre as familiaridades e estranhezas por ali dispostos, e a partir dos fios recolhidos no campo, (re)conheci a clínica como uma prática artesanal, uma feitura singular, com peculiaridades, aproximações e desvios próprios de um fazer que transborda a despeito dos enquadres. Durante essa incursão, a ação de pesquisar também se revelou como um processo artesanal, e emerge aqui como nossa principal questão.

Segundo o dicionário Houaiss ${ }^{1}$, o artesão é aquele que trabalha em oficina própria, não produz em larga escala e cada peça produzida apresenta-se de forma diferenciada. Ambas as práticas citadas convocam essa peculiaridade, pois, tal como no laboratório acompanhado por Latour (2000), o que acontece no campo de pesquisa e no espaço terapêutico não fica circunscrito ao binômio ação e reação. A matéria prima ali também se encontra sujeita a desvios e recalcitrâncias. Seguindo esta lógica, pensar a partir da premissa de que o que está em jogo são artesanias, faz-se também um ponto de conexão entre o fazer clínico e fazer pesquisa.

A inspiração artesanal à qual me remeto é a confecção de trabalhos manuais, feitos um a um, em que elejo como base a arte de tecer com fios, em especial a arte de "crochetar". Não faço crochê, todavia essa prática foi e é interferência na minha vida que se desdobra em interferências na minha atuação e é a ela que recorro como metáfora para o início desta narrativa.

Falar da minha escolha pela psicologia e em especial pela prática clínica remete-me a uma percepção longíncua, ao mesmo tempo que presente. A arte de trabalhar com fios e linhas atravessa muitas gerações na minha família. Vem desde a minha tataravó, exímia costureira especializada em camisaria masculina, crocheteira e bordadeira de mão cheia, até a minha mãe que se apoiava no crochê acreditando que ele era bom para tudo: para diminuir a ansiedade, melhorar a memória, driblar a depressão e também para preencher vazios. Ela repetia: "eu vou fazendo e o trabalho vai aparecendo. De repente eu tenho algo pronto e é bom ver o nosso trabalho ali, bonito, bem feito." Assim, essa prática constitui-se numa tradição, num conhecimento transmitido através de gerações, numa herança que merece ser reconhecida e respeitada. Vincienne Despret (1999) ressalta a importância de reconhecermos nossa herança pois ela funda o que construímos; negá-la completamente é retirar a base de onde partimos. O que é herdado torna-se um problema do qual não podemos simplesmente nos desfazer. Portanto esta herança torna-se, aqui, o ponto de partida.

\section{0 crochê como prática artesanal inspiradora}


Passei boa parte da minha infância observando minha mãe fazer crochê. Intrigava-me a rapidez de seus movimentos e os belos trabalhos que saiam de suas mãos com apenas uma agulha e meadas de linha. Tentei aprender mas não consegui alcançar os mistérios dessa prática. Vamos aqui, modestamente, apresentá-la.

O termo "crochê" é derivado da palavra francesa "croc", que significa gancho ${ }^{2}$ Esta é uma técnica/arte antiga, de origem imprecisa que consiste na prática de tecer com linhas a partir de uma agulha com a ponta em forma de gancho. Algumas pesquisas arqueológicas apontam para a China como sendo o local que apresenta o primeiro registro dessa prática, tendo alcançado mais tarde a Turquia, Índia, Pérsia, norte da África chegando finalmente ao continente europeu no século XVIII. Na Europa a técnica foi sendo modificada para o que os franceses chamam de "crochê no ar", onde o tecido de fundo e o bastidor foram abolidos e a agulha passou a ser trabalhada diretamente com a linha. A técnica foi sendo difundida, tornando-se o passatempo preferido das senhoras da nobreza, sendo praticada até pela rainha Vitória, embora, tradicionalmente, fosse atribuída às mulheres de classes populares. O primeiro e principal aprendizado do crochê é a trança ou corrente. Todos os pontos são criados a partir desse movimento. Assim a relação agulha, linha, mãos e atenção formam uma parceria constante para a criação e execução do trabalho.

O crochê exige uma sensorialidade que vai além do sentido da visão. As peças tecidas podem ser traduzidas em esquemas relativamente complexos que necessitam de uma noção do desenho da peça. Porém, como as peças formam um relevo, a mera visualização do esquema numa figura plana não é suficiente para compreendê-la. Fazer crochê envolve uma habilidade que imprime um sentido mais tátil à sua prática. Uma crocheteira experiente precisa conhecer as diferentes texturas das linhas e combiná-las à espessura das agulhas. A mesma peça pode ser confeccionada com linhas de diferentes cores. A troca de cores, no entanto, convoca uma manobra técnica para não comprometer a envergadura da peça. Tal manobra permite a articulação entre as linhas de modo que a peça mantenha sua harmonia. Além dessa possibilidade, uma peça pode ser confeccionada inteiramente com o mesmo ponto ou pode combinar pontos diferentes. Uma boa crocheteira deixa um trabalho perfeito, sem arremates visíveis. Tal façanha exige bastante dedicação e muitas horas de trabalho contínuo. É isso o que confere destreza à uma crocheteira: a prática! Além dos diferentes pontos, o crochê também pode ser realizado de diferentes formas. Tais formas são variações atravessadas por peculiaridades locais, adaptações culturais, mas derivam-se da técnica básica do crochê. Portanto, não é tudo a mesma coisa. 
A variedade de formas apresenta as diferentes técnicas possíveis na arte de crochetar. A construção desse trabalho foi inspirada nessa possibilidade e lançou mão de múltiplas intervenções que, assim como os diferentes crochês, dialogam entre si. O artesão inventa soluções. Para seguir, para mudar o feitio, para fazer o arremate de sua peça. Hoje percebo que escutar e interagir com pessoas tanto na prática clínica quanto no campo de pesquisa, é como tecer fios em rede. A história contada, é o fio da meada que vai formando pontos através dos diversos movimentos que fazem surgir vários tipos de peças. Às vezes enviesa, às vezes o ponto "foge" e talvez seja necessário desmanchar e refazer. Outra vez... outra vez... e outra vez.

Acompanhar processos como nos propõe a TAR, é um artesanato refinado tal e qual o crochê, que exige perseverança, paciência e humildade e pode convocar diversas ferramentas. É uma arte que se repassa "fazendo", cujos mistérios não estão num manual. Existem os pontos básicos, mas eles também podem ser inventados. Das invenções desenvolveram-se formas diferenciadas de técnicas, transformando espontaneamente o crochê numa arte de inventar. Assim como as crocheteiras, o pesquisador, por vezes, necessita achar outras formas de intervir e criar saídas para seus impasses.

\section{Fios, agulhas e esquemas}

Como já dito, as linhas podem se apresentar em diversas espessuras, cores e texturas. Dentre as opções disponíveis, existem as linhas matizadas que apresentam, em um mesmo fio, várias tonalidades de uma cor ou de cores diferentes. É uma configuração muito atraente ver os tons e as cores entrando uns nos outros, formando uma materialidade constantemente interferida. A experiência de pesquisar me remete a essa metáfora.

Desafios permanentes estiveram nesse trajeto de investigação, sendo que um dos maiores foi a minha própria realidade dentro do campo. Ao pesquisar a prática clínica, estava percorrendo um espaço bastante familiar para mim por atuar há muitos anos nesse segmento. O campo me habitava e, nesse momento da pesquisa, experimentei vários lugares e formas de habitar esse campo. Percebi que estava tornando minha experiência uma questão, problematizando minha herança, mapeando minha prática. Os questionamentos, então, estavam se transformando em minhas ferramentas para os movimentos realizados no campo. Desse modo, o reconhecimento e o confronto com essas questões foi o que me permitiu afirmar esse campo. Ao afirmá-lo, deixo de negar a história e a construção desse modo de fazer; ao afirmá-lo, legitimo as afetações e os afetos vividos durante o trajeto; ao afirmá-lo, passo a 
acolher minha bagagem, desconstruindo pouco a pouco a invalidação da experiência como fonte de conhecimento.

Tecer com diferentes linhas exige também um manejo das diferentes agulhas utilizadas para isso. Todo modo de ação interfere na tessitura do trabalho. Assim, os encontros que permitiram essa confecção passam por uma rede de pessoas, processos, leituras, discussões, escutas, tecnologias que é aprendido em função do tempo, um tempo de experimentação.

\section{Ferramentas convocadas para a ação de pesquisar: as agulhas que trançam os fios}

Começo a tecer apresentando o primeiro instrumento que me orientou: a TAR. A Teoria Ator-rede apresenta também a possibilidade de performar uma realidade múltipla, de estabilizações provisórias, talvez como um trabalho de crochê tecido com linhas matizadas A TAR define-se mais como um método do que uma teoria, um instrumento de investigação para os eventos que vão além dos fatos e atravessam a vida cotidiana numa articulação híbrida no fluxo da experiência.

Latour (1994) aponta que estamos envolvidos num mundo de objetos híbridos, onde não cabe mais o predomínio da clássica dicotomia entre indivíduo e a sociedade, ciência e natureza, sujeito e objeto. Sofremos inúmeras interferências que afastam a idéia de um conhecimento puro, livre de afetações. Segundo Moraes (2003)

A noção de rede não é, para Latour, oposta à dicotomia moderna. Mas é aquilo que nos faz passar ao largo destas dicotomias. A noção de rede encontra ressonâncias filosóficas com o trabalho de M. Serres e de Deleuze e Guattari. É o próprio Latour que indica que a noção de rizoma é uma palavra perfeita para rede. Uma rede é um mapa, e não um decalque, quer dizer, que a rede de atores é aberta, heterogênea de modo que a princípio é possível estabelecer todo e qualquer tipo de conexão, sem que seja uma necessidade de direito a redundância de elementos-chaves. $\mathrm{Na}$ linguagem de Latour podemos dizer que rede é sinônimo de híbridos, de quase objetos. Enquanto a lógica da modernidade é a lógica do decalque, a lógica da rede é aquela do mapa. (p. 1-2)

Segundo a Teoria Ator-rede, um ator é tudo e todos que agem numa rede incluindo humanos e não-humanos, ou seja, é tudo o que possa gerar algum impacto na rede. Desta forma, uma ação nunca está concentrada num único ator e, portanto, é resultante de diversas conexões e também não se fecha em si mesma. Ela pode ser 
retomada, revisada, desconstruída e reconstruída em qualquer ponto. Latour (2000), na verdade, prefere usar o termo actantes que expressa melhor a idéia de ação. Actantes atuam na rede ao mesmo tempo que a configuram. Ele ressalta, ainda, que uma das características principais dessas redes constituídas por ações, efeitos, é justamente sua imprevisibilidade, pois elas são totalmente heterogêneas. Latour (2008) destaca, ainda, que um estudo Atorrede envolve, pelo menos, cinco tipos de incertezas que devem ser consideradas e estão aqui sintetizadas:

1) Não há estabilidade nos grupos ou redes. Os atores se deslocam e se reagrupam com freqüência. Torna-se, então, impossível atribuir um perfil conclusivo, duradouro, visto que o grupo não existe enquanto entidade, mas sim como processo; 2) As ações sofrem interferências provenientes de diversos agentes, nem todos visíveis e, portanto, não facilmente identificáveis Latour enfatiza que a ação deve seguir sendo uma surpresa, uma mediação, um evento (op cit. p.72).O social não é algo em si, mas é uma construção que abrange diversidades; 3) Como conseqüência desta multiplicidade e de seu caráter dinâmico, há um crescimento constante da lista de entidades envolvidas no curso de uma ação. Tal fato exige que estejamos o tempo todo revendo quem são os participantes dos eventos que estão sendo acompanhados. Isso inclui humanos e não-humanos, o que nos leva a rever a premissa de que as relações só acontecem entre pessoas; 4) Isso produz uma indefinição do campo do saber, podendo envolver diversas disciplinas na investigação. A fragmentação dos saberes é nociva para tal investigação pois os campos de conhecimento se entrecruzam com fronteiras flexíveis; 5) A elaboração dos relatórios de pesquisa torna-se um desafio visto que, neste enfoque, não podemos reconhecer algo que seja exclusivamente humano ou exclusivamente pertencente a um único campo de conhecimento.

Estar diante dessas incertezas provoca mudanças na postura do pesquisador. Em algum nível, ao propor que se abra mão de um quadro de referências, de uma teoria ou de uma hipótese a priori de pesquisa, Latour abre caminho para se pensar a pesquisa (e também os fatos observados) como experimentações do trajeto. A essa redistribuição da agência no campo corresponde, sobretudo, uma redistribuição dos saberes entre o pesquisador e o campo. 0 pesquisador despe-se de seu jaleco branco e se entrega ao fluxo do movimento de seu trabalho. A premissa de seguir os atores, proposta por Latour, implica a disponibilidade do pesquisador em movimentarse na rede permitindo-se ser afetado pelas conexões por ela produzidas. Essa pode ser uma reversão da idéia de neutralidade, porém não significa que o pesquisador se perca de seu propósito ou que seja simplesmente capturado pela rede. 
John Law e John Urry (2005) e Annemarie Mol (2007), juntos a Isabelle Stengers (2002) e Despret (1999; 2011a; 2011b), por sua vez, tomam essa versão em seus efeitos refletidos sobre o próprio fazer ético-político do pesquisador. O pesquisador torna-se também um actante que interfere na rede. Quando ele escolhe um caminho dentre os muitos que podem se apresentar no movimento do campo, produz uma interferência que vai reverberar no mundo e que pode se desdobrar num efeito de verdade a produzir realidades e agenciamentos que destacam e naturalizam certos elementos e deixam outros de fora. A idéia de que interferimos na produção de realidades construídas e provisórias a partir de acontecimentos que emergem no processo nos leva a ter uma atitude de atenção às nossas ações e percepções para não corrermos o risco de desqualificarmos ou ignorarmos eventos dentro do nosso campo de ação. Isso exige generosidade e sensibilidade para refazermos trajetos ou desvios que podem ser inevitáveis numa metodologia que inclui atores e actantes como detentores de um saber próprio.

A Teoria Ator-rede destaca as realidades que se fazem possíveis em determinadas condições, redistribuindo, constantemente, o que está sendo priorizado e o que está presente mesmo sem estar no foco. Essa alteridade presença/ausência, nos leva a questionar como esse processo se organiza e o modo ativo de acompanhar, transforma a ação do pesquisador numa escolha política uma vez que alguns aspectos se evidenciam e outros se obscurecem nesta rede. Sobre esse aspecto, J. Law (2004) ressalta que o pesquisador produz mundos e realidades, gerando responsabilidades inerentes sobre sua forma de abordar os movimentos da rede. Deste modo, para o autor, as estabilizações não seriam fundamentais, mas sim as formas de conexão e as percepções dos envolvidos na rede. Não podemos representar a realidade sem considerar aquele que a representa.

Quando elegemos o que será colocado em foco, assumimos também um posicionamento que deriva das implicações e dos modos como nos engajamos em nossas pesquisas. Assim, nossas ações passam a envolver uma Política ontológica (Mol, 2007; Law 2004) que faz emergir uma realidade sobre a qual temos responsabilidade. Corremos o risco de sermos capturados pelas tendências hierarquizadas e categorizantes. Portanto, atuar com essa metodologia implica numa reformulação da nossa própria formação fundada na tradição de representar um suposto saber erudito, separado do senso comum e entronizado como conhecimento superior. Transitar pela rede e manter uma investigação ativa, viva e vibrante nos retira da convencionalidade e nos permite uma ação mais inventiva.

Nosso tráfego já carrega um intervir pois não permanecemos mero observadores do movimento desta rede, mas estamos incluídos, identificando vínculos e negociando espaços. Esta é, de fato, uma 
outra abordagem em ciências sociais. Esta presença ativa e interventiva, no entanto, deve resguardar a genuinidade e espontaneidade dos movimentos, pois, se passarmos a conduzi-los, imprimiremos um caráter artificial e manipulador retomando o lugar de um poder autoritário por vezes outorgado ao cientista ao longo da história. Assim, acompanhar vivenciando sem deixar de lado a ação de pesquisador pode constituir uma intervenção sutil, porém impactante. Não há como estar "retirado" neste processo; não há roteiros pré-concebidos, mas há como mapear o trajeto, lembrando que o mapa não é o território em si, mas sim um conjunto de referências imprecisas, porém norteadoras.

A metodologia proposta retira o cientista das certezas sem, necessariamente, destituí-lo de seu conhecimento. Ele agrega, mas não impõe, ele reconhece, mas não desqualifica, ele se integra, mas, sobretudo, aprende. Funda-se numa relação de respeito, curiosidade, envolvimento e criatividade. Essa pode ser uma aventura que exige despojamento, valida a porção inventiva da produção de conhecimento e nos aproxima finalmente da arte enquanto campo de criação, enquanto poiésis.

É, então, a partir dessa primeira agulha tomada para iniciar esse crochê que interfere na minha postura de pesquisadora, que me vejo costurando as práticas de pesquisa e de clínica enquanto intervenções simétricas e poéticas. Todavia, considerando que o manejo do campo (seja ele clínico ou de pesquisa) gera sempre necessidades particulares a ele, tive que ir em busca de outros meios e encontrei em outras metodologias modos de intervir que se articulam, fazem parceria com a teoria ator-rede. Durante a pesquisa, muitas memórias foram evocadas e atravessaram esse processo sem roteiro ou planejamento prévios. São histórias vindas da minha experiência, mas que foram recrutadas no campo. Este campo, então, constituiu-se num dispositivo que fez e emergir essas memórias passadas, na ação presente. Buscando responder o que é um dispositivo, Deleuze (1990) afirma,

Em primeiro lugar, é uma espécie de novelo ou meada, um conjunto multilinear. É composto por linhas de natureza diferente e essas linhas do dispositivo não abarcam nem delimitam sistemas homogêneos por sua própria conta (o objeto, o sujeito, a linguagem), mas seguem direções diferentes, formam processos sempre em desequilíbrio, e essas linhas tanto se aproximam como se afastam uma das outras ( $p$. 1)

Deleuze (op cit) afirma ainda que as duas primeiras dimensões de um dispositivo destacadas por Foucault, são as curvas da visibilidade e as curvas da enunciação. Os dispositivos são como "máquinas de fazer 
ver e fazer falar" (op cit, p. 1). A visibilidade não significa dar luz ao que estava obscuro; antes, ela emerge no processo de relações que vão se estabelecendo na rede, criando possibilidades de delinear novas formas, "Cada dispositivo tem seu regime de luz, a maneira em que esta cai, se esvai, se difunde ao distribuir o visível e o invisível, ao fazer nascer ou desaparecer o objeto que não existe sem ela." (op cit, p.1). As histórias que surgiram foram fruto de um diálogo travado no campo. Meus interlocutores em suas próprias falas, puxaram lembranças que no relato de pesquisa apresentam-se como desdobramentos singulares que se misturam a tantas histórias compartilhadas.

Portanto, a imersão nesse campo foi uma grande provocação. As histórias que passaram a me rondar exigiam um espaço para se manifestarem. Pelo que colhi nessa trajetória de estudos, ser tocado pelo campo é uma contingência inerente ao processo de pesquisarCOM (Moraes, 2010). Nesse sentido, as histórias e acontecimentos aparentemente distantes no tempo, aproximaram-se subitamente, vindas dos entrelaçamentos entre as vivências atuais no campo e as experiências pregressas. Muitas vezes tive a impressão de que não eram simples memórias. Apoiado na teoria do caos, Serres (1999) defende que o tempo não é linear: "O tempo escoa de maneira extraordinariamente complexa, inesperada, complicada... Paradoxal, o tempo se dobra ou se torce".(p. 79). Foram essas dobras do tempo que aportaram (e suportaram) tais memórias. E uma nova laçada vai fazendo crescer a tessitura desse crochê.

A proximidade com o campo e a aproximação das lembranças colocam-me diante de mais um instrumento fundamental para que eu possa seguir crochetando: a História Oral. Ao referir-se à História Oral e à História do Tempo Presente, isto é, a dois modos de fazer história onde o tempo decorrido entre os fatos passados e o presente não é longo, Chartier destaca a importância da integração do historiador ao seu campo, considerando tal aproximação como a virtude da investigação e não como falha de atuação, pois "O pesquisador é contemporâneo de seu objeto e divide com os que fazem a história, seus atores, as mesmas categorias e referências. Assim, a falta de distância, ao invés do inconveniente, pode ser um instrumento de auxílio importante para um maior entendimento da realidade estudada, de maneira a superar a descontinuidade fundamental, que ordinariamente separa o instrumento intelectual, afetivo e psíquico do historiador e aqueles que fazem a história (Chartier como citado em Ferreira, p.18, 1996).

O envolvimento não é um despreparo do pesquisador. Este é, muitas vezes, um requisito para que o pesquisador trave um diálogo entre as próprias impressões, a experiência vívida, a fluidez do campo, as referências epistemológicas e a emergência dos atores que atravessam este processo. Estar "dentro" constitui um outro possível 
apoiado na horizontalidade do "falar de" e/ou "falar com" que se diferencia da verticalidade do "falar sobre". Na minha atuação, ao utilizar as entrevistas fazendo com o que o entrevistado retomasse sua própria história, percebi que estava adentrando a vida, a pessoalidade daqueles que aceitaram me contar o que teceram na clínica. O relato contém uma força que não se restringe à palavra. $\mathrm{Na}$ oralidade há o caráter móvel das palavras que podem ser transformadas, reformuladas ao longo do discurso. Os hiatos, as pausas e os silêncios são "falantes", imprimindo uma vivacidade e um "dizer" intensificado pela ação. A mobilidade do discurso, no entanto, não o desqualifica como dado; ao contrário, nos é oferecido um dado vivo, pois rememorar é também produzir em alguma escala. O campo resgatou uma memória viva, convidando-me a participar de várias formas e trazendo também para o entrevistado um confronto com sua história. A memória, então, é um ator (ou melhor, uma atriz) que entra nessa rede (re)ativando sensações, emoções e pensamentos que se articulam às outras memórias, fazendo desse um trabalho coletivo, uma colcha com muitos tecidos e linhas entrelaçadas.

\section{Tecendo histórias com o fio da memória}

Transitando pelos caminhos da história oral, deparo-me com a memória como uma força de atuação. Se numa versão mais tradicional existem dúvidas quanto a sua confiabilidade, são elas que abrigam o sentido das experiências vividas. Thomson (1997), destaca que "compomos nossas reminiscências para dar sentido à nossa vida passada e presente" (p.56). A composição é uma articulação de lembranças e significados que se expressam numa linguagem referenciada em nossa cultura. Assim, ao mesmo tempo em que ela é um processo singular, ela pode se instaurar no coletivo. Parte de nossa história se sustenta em nossa memória. Mas isso se refere unicamente ao passado? Segundo Thomson, "A memória gira em torno da relação passado-presente, e envolve um processo contínuo de reconstrução e transformação das experiências relembradas" (1997, p.57). As entrevistas realizadas no campo puxaram também fios da memória dos entrevistados, num movimento de rememorações que produziu interseções entre os relatos. Os questionamentos efetuados nas entrevistas traçaram um movimento constante entre o que aconteceu, o que está acontecendo e o que ainda poderá acontecer. Do mesmo modo, todo esse tempo se desdobra ou se redobra agora em função do processo dessa escrita e novamente no processo ativo de leitura.

Essa experiência nos remete mais uma vez à Serres (1999) que nos diz que qualquer acontecimento da história é multitemporal. Nessa condição, o tempo é "multiplamente dobrado" (p.82) e os pontos do 
passado, presente e futuro podem se encontrar e se afastar sem uma linearidade. As dobras do tempo, ou essa "variedade amassada", possibilita o espaço para um diálogo entre as experiências vividas sem a barreira de um tempo seqüencial. O surgimento de lembranças convocadas pela memória permite também uma reintegração de acontecimentos que, por razões diversas, possam ter sido menos valorizados, ou editados, no decorrer do tempo. Assim, ao recontar ou rever uma história, um fato "novo" pode ser resgatado, um sentido pode ser reconfigurado, uma outra versão pode ser construída. Na tradição oral isso fica ainda mais evidente, visto que, na oralidade, refazer o dito está ao alcance imediato de quem o diz. Aparentemente, tal característica pode colocar o que é dito sob suspeita. Mas se é verdade que, como aponta o velho ditado (lembrando que os ditos populares fazem parte de uma memória coletiva), "quem conta um conto, aumenta um ponto" há um outro que nos diz que "o povo aumenta, mas não inventa". Assim, considerando a própria herança constituída pela tradição oral, contar e escutar histórias podem ser compreendidos como uma força. Ressaltamos que, na prática clínica, são as falas e as escutas que estabelecem as intervenções, ratificando o diálogo como recurso de atuação.

A entrevista aqui utilizada como recurso não teve, como finalidade, colher dados para análise, mas sim para fazer emergir narrativas que nos permitisse criar um diálogo, pois os entrevistados "não são objetos da investigação, mas sujeitos de um projeto compartilhado, de um diálogo entre entrevistado e entrevistador. Um diálogo em que os papéis se modificam, mudam, em que nem sempre é o historiador quem faz as perguntas, há perguntas colocadas pelo entrevistado" (Portelli, 2009 p.2).

Ao compreendermos esse processo de entrevistar como um diálogo, tanto o entrevistador quanto o entrevistado colocam-se diante do risco. Todos fomos afetados: eu, os entrevistados e as estudantes que transcreveram as entrevistas. Portelli (op.cit), acredita que, quando tanto o entrevistado quanto o entrevistador não saem diferentes após a entrevista, ela não desenvolveu todas as potencialidades do encontro. No encontro pleno, o entrevistador aprende algo mais, o entrevistado reflete e organiza sua narrativa, revê sua própria história tornando esse momento uma oportunidade rica para os envolvidos.

Começo a me deslocar um tanto ansiosa frente à tensão desses encontros, mas menos "apressada", disposta a apreciar a multiplicidade de fios e receber o que eles puderem oferecer, reconhecendo as diferenças de textura e experimentando as agulhas que estiverem ao meu alcance, atenta e viva a cada momento e a cada laçada. Esse trabalho reflete esta experiência singular, polifônica e intensa. Às vezes torna-se necessário criar modos de orientação. 
Muitos pontos mais sofisticados no crochê são transpostos em esquemas de orientação, uma espécie de mapeamento do que está sendo tecido. Assim, lanço mão de mais um instrumento: a cartografia.

\section{Crochetando com os fios do campo: a convocação do fazer}

Na perspectiva de Kastrup e Pozzana de Barros (2009), cartografar é acompanhar processos. E qual é o sentido dessa prática? Acompanhar, estar junto, perceber, embrenhar-se, implicar-se, são tarefas que exigem muito de quem as realiza. Se, por um lado, podemos experimentar a surpresa, o aprendizado e a alegria do compartilhar, por outro estamos entregues, desprovidos de garantias, às forças e aos fluxos dos movimentos do campo sem, no entanto, desconsiderar que nós ali, também constituímos uma força. Ao nos dispormos a acompanhar, nos incluímos no campo e passamos, portanto, a problematizar nossa inclusão, nosso envolvimento. Segundo Amador e Fonseca (2009),

A cartografia apresenta-se como procedimento de pesquisa que exige do pesquisador posturas específicas. Convoca-o para um exercício cognitivo peculiar, uma vez que, estando voltado para o traçado de um campo problemático, requer uma cognição muito mais capaz de inventar o mundo. Trata-se de uma invenção que somente se torna viável pelo encontro fecundo entre pesquisador e campo pesquisa, pelo qual o material a pesquisar passa a ser produzido e não coletado, uma vez que emerge de um ponto de contato que implica um deslocamento do lugar de pesquisador como aquele que vê seu campo de pesquisa de um determinado modo e lugar em que ele se vê compelido a pensar e a ver diferentemente no momento mesmo em que o que é visto e pensado se oferece ao seu olhar (p.31 grifo nosso)

Nesse sentido, a entrada no campo de pesquisa requer o desapego ao que estamos levando e a disponibilidade para o que podemos encontrar. É nessa fronteira de contato que a pesquisa pode se constituir.

Quando nos defrontamos (ou confrontamos) ${ }^{3}$ com o campo, acessamos não exatamente o desconhecido, mas o despreparado, 0 ainda não feito, o imprevisto, o não inventado também em nós. Essa é, de fato, a grande aventura e, ao mesmo tempo, o risco que corremos. Se não podemos garantir o que iremos encontrar lá, não podemos prever o que acontecerá em nós. Ao buscar a cartografia com recurso, volto-me mais uma vez à Amador e Fonseca (op.cit) 
quando elas nos dizem que "seu fazer se faz por des(fazimento), por uma espécie de disposição de (des)aprontar-se, de modo a sintonizar com os percursos processuais que se constituem em seu objeto. Como fazê-lo, senão adotando uma postura intuitiva?"(op.cit, p. 33). Apoiadas em Bergson, as autoras definem intuição como sendo "a consciência imediata, visão que quase não se distingue do objeto visto" (op.cit, p. 32). Vindo de Bergson e passando por Deleuze, elas concluem que o trabalho do cartógrafo requer mais da intuição do que da inteligência, ressaltando, porém, que ambas não podem ser efetivamente separadas. Dessa forma, "o trabalho do cartógrafo exige do pesquisador, antes que definições técnicas, uma experimentação na própria duração" (op.cit, p. 33, grifo nosso).

A relação tecida no campo vai também estabelecendo nossos modos de intervenção. Se isso é conjugado no gerúndio, ou seja, uma ação que vai se fazendo, há um aspecto artesanal nessa prática. Existem circunstâncias e situações que geram a necessidade de inventar. Em "A clínica da reconstrução" 4 Despret (1996), em sua experiência de implementação de um programa de ajuda humanitária num campo de refugiados da ex Iugoslávia, ao perceber, no campo, a impossibilidade de seguir os passos definidos pelo programa ela e sua equipe se permitem inventar, a partir de intervenções mal sucedidas, o que ela chamou de "terapia dos espaços em branco." 5 Os espaços em branco são, segundo a autora, "os espaços de liberdade, de criatividade ou de adaptabilidade que autorizam a flexibilidade do corpo teórico que o programa" 6 (op.cit,p. 159).

Desse modo, as forças que utilizei nessa pesquisa, vieram de três elementos fundamentais: 0 interesse pelo campo, a disponibilidade para rever conhecimentos e receber o que o campo oferecia, e a sensibilidade para perceber o que se presentificava nos processos de experimentação que traziam a potência para inventar. Aproximar a metodologia ao crochê, essa arte manual, sujeita tanto às imperfeições e repetições quanto à maestria e aos ineditismos, é uma junção de mundos que interferem na minha experiência. O crochê é uma prática que se aprende fazendo. Pode começar pela observação de quem faz, mas o sentido do fazer só se realiza na ação local, encarnada, inventiva e ética. O aprendiz pode se inspirar no mestre observado. Porém, o trabalho não é uma pura reprodução. Quem o executa, imprime a sua marca. Na pressão com que usa a agulha, na qualidade das linhas escolhidas e na mudança de traçado que pode ocorrer no ato de crochetar. Assim, não é imitação, torna-se uma reinvenção que emerge da singularidade de cada fazer.

A partir do que foi experimentado e construído nesse campo de pesquisa, recorro à Alvarez e Passos (2009), para organizar o que aprendi. Os autores compreendem o campo e a prática de pesquisa como um espaço de produção de conhecimento destacando que “conhecer não é tão somente representar o objeto ou processar 
informações acerca de um mundo já supostamente constituído, mas pressupõe implicar-se com o mundo, comprometer-se com a sua produção" (p. 131). Dessa forma, o conhecimento se produz nesse engajamento do pesquisador com seu campo. O campo possui uma vivacidade e uma capacidade de interferir nos rumos que o trabalho poderá tomar. O que organizamos vai sendo transformado no curso da experiência, pois, "é sempre no compartilhamento de um território existencial que sujeito e objeto de pesquisa se relacionam e se codeterminam" (op.cit., p. 132).

Assim como quem prática o crochê, não é possível simplesmente reproduzir uma ação. Cada trabalho tem uma envergadura. A cartografia nos oferece a idéia das pistas como possibilidade de acompanhar um processo (Kastrup, Passos, \& Escóssia, 2009). Com essa inspiração, vou arriscar mapear as pistas desse trabalho, porém compreendendo-as como pontos de crochê construídos durante esse crochetar/pesquisar que vêm permeando esse trabalho. Permitamme, então, uma modesta ousadia nesse trecho final:

\section{Ponto do Reconhecimento: Reconhecer a herança}

O fio puxado para o desenvolvimento desse trabalho partiu fundamentalmente da minha emoção. A consciência da herança recebida, a parceria com as mulheres que me antecederam (e também pelas que me atravessaram como Despret, Mol e Moraes) e o reconhecimento da legitimidade da experiência, do vivido na minha trajetória profissional. Percebi que a emoção é um dos meus instrumentos fundamentais de trabalho. Por tudo que venho recolhendo (e acolhendo) durante essa trajetória, compreendo-a como aliada. Não preciso mais domesticá-la. Ela é uma forma legítima de ler o mundo e não precisa ser colocada como oposição à razão. O trânsito pela pesquisa requer um refinamento, uma sensibilidade mais delicada. Receber o campo é também senti-lo. Assim ao adentrarmos um campo de pesquisa levamos a totalidade de nossas experiências, o que inclui o conhecimento, os contornos pessoais, a história de vida, enfim, o que sabemos, o que sentimos e o que vivemos. Isso nos constitui e constitui o nosso campo.

\section{Ponto das afecções: Permitir-se ser afetado e afetar, reconfigurando o campo}

Atuar no campo com esse instrumental mais aberto e flexível implica em correr riscos. É necessário o desapego dos conceitos tanto de sucesso quanto de fracasso. O campo de pesquisa não deve se restringir às confirmações, mas, ao contrário, pode se afirmar como campo de incertezas. É nos mal entendidos que podemos produzir bons conhecimentos. É para o que fica de fora que devemos voltar nosso interesse (Despret, 2011b). Os equívocos vividos no início da minha prática clínica são formadores desse trabalho. Assim, o 
movimento da prática traz constantes deslocamentos que nos levam a desvios e retornos. Não é possível, nessa referência, seguir somente em linha reta. Rever, reconhecer, retificar, refazer, rememorar e reconfigurar, revelam-se movimentos necessários quando nos colocamos nessa ação de acompanhar. O acompanhamento é ativo, processual, e, sobretudo, exige disponibilidade para inventar.

\section{Ponto da expressividade: Compartilhar um território existencial}

Extraio essa ponto/pista de Alvarez e Passos (2009) que, fundamentados em Deleuze e Guattari, falam de território não a partir de sua funcionalidade e sim de sua expressividade. A expressão não se restringe ao pertencimento ou propriedade. Ela tem autonomia. Assim, não falamos de um território meramente espacial, mas ele se constitui pelo que emerge na experiência, compreendendo-a através da circularidade e reflexividade. Acessar "paisagens" e "personagens" (op.cit), incluindo o pesquisador, exige que ele habite esse território e se disponha ao aprendizado. Não um aprendizado em série de etapas, "mas como um trabalho de cultivo e refinamento" (p.135). Como os autores ressaltam, isso se constrói no processo de pesquisa. A receptividade, a emoção, a implicação e o engajamento, nos permitem essa possibilidade.

\section{Ponto COM: Entregar-se à arte de pesquisarCom}

O pesquisarCom proposto por Moraes (2010) afirma a pesquisa como prática performativa e nos convoca a "acompanhar este processo em ação, se fazendo na prática cotidiana daquelas pessoas que 0 vivenciam"(p.42). Privilegiar as práticas nos permite seguir os modos de produzir realidades nos levando a interferir neles. Ao trazer para esse texto questões relativas ao dinheiro e à supervisão na clínica, por exemplo, busquei apontar questões que emergiram nesse processo. Ao localizá-las e colocá-las em cena, ordenei acontecimentos de um modo novo para mim. Foram questões articuladas pelas falas dos entrevistados que se reuniram às minhas vivências. Mas as questões aqui propostas só foram possíveis nessa circunstância da pesquisa. Assim, trabalhar com o campo, abre espaço para o que o campo pode dizer e potencializa novos conhecimentos constituídos numa ação coletivizada. Fazer com nos possibilita dizer ao outro, a partir de um diálogo, sem legislar sobre o proposto. Moraes (2011) ${ }^{7}$ destaca a importância de criarmos dispositivos que nos permitam transformar um ao outro pesquisador e pesquisado - ressaltando que "como fazer bons dispositivos?" é uma pergunta que nunca pode ser respondida, mas sempre deve ser colocada... Esse é o desafio para uma prática que se faz no desdobrar dos acontecimentos. 


\section{Ponto do cuidado: Decidir como quem cuida}

A pesquisa sempre parte de algum lugar e, nesse sentido, ela é local, como nos diz Latour (2008). Se não existem permanências nesse modo de intervir na pesquisa, se não buscamos verdades, o que podemos afirmar enquanto pesquisadores? No processo de conhecer, os elementos que definimos como partícipes da cena, isto é, que resolvemos delinear, mesmo que os digamos convocações do campo, partem de escolhas e decisões que assumimos durante o processo de pesquisar. Assim, as decisões devem envolver um cuidado. Cuidar, aqui, refere-se à noção dos efeitos que tais decisões podem gerar. Portanto, espera-se que o pesquisador tenha algo a dizer, uma descoberta para compartilhar, ou uma conclusão para definir. Como e o que dizer, pode fazer (e faz!) toda diferença. Se generalizarmos uma afirmação, não só ela se dilui como perde sua força. Assim, a afirmação tem um sentido estrito ao campo onde ela se constitui. Porém, o que ocorre nesse lugar reverbera, cria impactos numa rede de conexões e nos permite refletir acerca dos acontecimentos que estão à nossa volta. Portanto, quando tomamos um posicionamento assumimos uma responsabilidade, respondemos pelo que está sendo produzido a partir do campo. É o que Mol (2007) chama de política ontológica. E, no nosso caso, ela é, muitas vezes, uma política narrativa. O que escrevemos no texto que produzimos é, portanto, uma ação política não isenta de críticas e julgamentos. As palavras, então, são instrumentos e as narrativas são forças que podem interferir nas práticas e nas relações, nas pessoas. Cuidar, então, é manter-se atento, dar-se conta de que esse é um processo coletivo, exige que tenhamos clareza do poder que exercemos. Cuidar é manter a sensibilidade sobre esses efeitos.

Ao discorrer sobre esse aprendizado compartilho, emocionada, a intensidade dessa experiência que foi maior e mais profunda do que pude, antes, imaginar. No movimento do crochê há uma repetição de pontos, porém se eles forem mecanizados e enrijecidos, o risco de errar e de o crochê "embabadar" (perder a forma) é grande. Portanto, o trabalho é uma repetição, mas, como dizem as crocheteiras, é preciso senti-lo, perceber que ele está crescendo, vêlo aparecer, ou melhor, vir a ser a peça acabada. A paciência é essencial, o tato é necessário, a atenção é fundamental e a capacidade de contemplar emerge desse ato de tecer a peça. Não estaria eu finalmente aprendendo o ofício de fazer crochê?

\section{Referências}

Alvarez, J. \& Passos, E. (2009). Cartografar é habitar um território existencial. In: V. Kastrup, E. Passos, \& L. Escóssia (Orgs.). 
Pistas do método da cartografia - Pesquisa intervenção e produção de subjetividade (pp.131-149). Porto Alegre: Sulina.

Amador, F.\& Fonseca, T. G.(2009). Da intuição como método filosófico à cartografia como método de pesquisa considerações sobre o exercício cognitivo do Cartógrafo. Arquivos Brasileiros de Psicologia, 61(1), 30-37.

Chauvenet, A., Despret; V, \& Lemarie, J. M. (1996). Clinique de la Reconstrution. Paris: L'Harmattan.

Deleuze, G.(1990). O que é um dispositivo? In: M. Foucault, filósofo. (Wanderson F. Do Nascimento, Trad.) Recuperado em 28 de agosto, 2011, de www.escolanomade.org

Despret, V. (1996) Thérapie des espaces blancs in CHAUVENET, A.; DESPRET, V.; LEMARIE, J. M. (orgs) Clinique de La reconstruction, p.159-194, Paris, L' Harmattan

Despret, V. (1999). Ces emotions qui nous fabriquent. Paris: Empecheurs Penser.

Despret, V. (2011a). Leitura Etnopsicológica do segredo, Dossiê Despret. Revista Fractal de Psicologia, 23(1), 5-28.

Despret, V. (2011b). As ciências das emoções estão impregnadas de política? Dossiê Despret. Revista Fractal de Psicologia, 23(1), 29-42.

Ferreira, M.M. (1996). A História Oral do Tempo Presente. In J. C.S.B. Meihy (Org.). (Re)Introduzindo a História Oral no Brasil (pp.1121). S. Paulo: Xamã.

Kastrup, E. Passos, \& L. Escóssia (2009) (Orgs.). Pistas do método da cartografia - Pesquisa intervenção e produção de subjetividade, Porto Alegre: Sulina.

Kastrup, V., \& Pozzana de Barros, L. (2009). Cartografar é acompanhar processos. In V. Kastrup, E. Passos, \& L. Escóssia (Orgs.). Pistas do método da cartografia - Pesquisa intervenção e produção de subjetividade (pp.52-75). Porto Alegre: Sulina.

Latour, B. (1994). Jamais fomos modernos: Ensaio de Antropologia Simétrica. (C.I, Costa, Trad.). Rio de Janeiro: Editora 34. (Nous n`avons jamais eté modernes em 1994)

Latour, B. (2000). Ciência em ação: como seguir cientistas e engenheiros sociedade afora. (Benedetti, I. C., Trad.). São Paulo: UNESP, 2000. (Science in Action, 1998)

Latour, B. (2008.) Reensamblar lo social: uma introdución a la teoria del actor-red. (G. Zadunaisky, Trad.). Buenos Aires: Manantial. (Reassembling the Social - An Introduction to Actor-Network Theory em 2005).

Law, J. (2004). After Method: Mess in social science research. New York: Roultledge.

Law, J, \& Urry, J.(2005) Enacting the social. Economy and Society, v. 3, n. 3, p. 390-410. 
Mol, A. (2007). Política ontológica. Algumas idéias e várias perguntas. In J. A. Nunes, \& R. Roque (Orgs.). Objectos impuros: experiências em estudos sociais da ciência. (pp.22-40). Porto: Edições Afrontamento.

Mol, A. (2008). The logical of care: Health and the problem of patient choice. London: Routledge.

Moraes, M. (2003). Alianças para uma Psicologia em Ação: sobre a noção de rede. Recuperado em 24 de setembro, 2009, de www.necso.ufrj. br/Ato2003/MarciaMoraes. htm

Moraes, M. (2010). PesquisarCOM, Política Ontológica e dediciência visual, In M. Moraes, \& V. Kastrup (Orgs.).O Exercício de ver e não ver (pp.26-51). Rio de J aneiro: Nau.

Moraes, M.(2011). Pesquisar: verbo ou substantivo? Narrativas de ver e não ver. Pesquisas e Práticas Psicossociais, 6(2), 174181.

Portelli, A.(2009). Conferência História Oral e Poder- XXV ANPUH Fortaleza, CE. Recuperado em 14 de setembro, de alessandroportelli-blogspot.com. br/ postado em 2010-12-01.

Quadros, L. C. T.(2011). A construção artesanal do fazer clínico em Psicologia, Tese de doutorado, Programa de Pós-graduação em Psicologia Social da UERJ, Rio de Janeiro, RJ, Brasil.

Serres, M. (1999). Luzes: cinco entrevistas com Bruno Latour, S.Paulo: Unimarco.

Stengers, I. (2002). A invenção das ciências modernas, S. Paulo: Ed. 34

Thomsom, A. (1997). Recompondo a Memória-Questões entre a História Oral e as memórias. Projeto história (15), 51-84.

\section{Endereço para correspondência \\ Laura Cristina de Toledo Quadros}

Universidade do Estado do Rio de Janeiro

Instituto de Psicologia - Programa de Pós Graduação em Psicologia Social

Rua São Francisco Xavier, 524, 10 andar, Maracanã, CEP 20550-013, Rio de Janeiro - RJ, Brasil

Endereço eletrônico: lauractq@gmail.com

Recebido em: 16/05/2014

Reformulado em: 24/09/2014

Aceito apra publicação em: 29/09/2014

\section{Notas}

* Professora visitante do Instituto de Psicologia e do Programa de Pós Graduação em Psicologia Social UERJ, Rio de Janeiro, RJ, Brasil. Doutora em Psicologia Social PPGPS- UERJ; Mestre em Psicologia Social e da Personalidade ISOP/FGV/UFRJ; Especialista em Psicologia Clínica CRP; Vice-coordenadora do projeto de extensão Laboratório Gestáltico: Configurações e práticas contemporâneas.

${ }^{1}$ Houaiss on line, disponível em www.uol.com. br, acesso em 6 de agosto de 2009.

2 Não há uma literatura científica acerca desse tema. As informações aqui contidas foram filtradas de sites: http://pt. wikipedia.org/wiki 
3 Os significados desses dois vocábulos são bem próximos, com uma sutil diferença; cofrontar: por-se frente algo ou alguém; estar frente a frente com situação de divergência; enfrentar- defrontar: ver-se frente a frente algo ou alguém; encontrar-se defronte; enfrentar. (in Aulete, disponível em $<$ www.uol.com.br>, -grifo meu). No campo de pesquisa, as duas situações - a divergência e o estar de frente- são possíveis e produzem efeitos diferenciados.

${ }^{4}$ No original Clinique de la Reconstrution, 1996.

${ }^{5}$ No original Thérapie des espaces blancs.

6 No original Ces espaces blancs sont les espaces de liberté,de créativité ou d'adaptabilité qu'autorise la souplesse du corpus théorique structurant le programme. (p.159)

${ }^{7}$ Afirmação oriunda de discussão no grupo, registrada em anotações pessoais. 